\title{
VIABILIDADE ECONÔMICA DA SUINOCULTURA NO SISTEMA WEAN TO FINISH EM SÃO JOSÉ DO RIO PARDO - SP
}

\author{
Mariane Zabotto Evangelista ${ }^{1}$
}

Rafaela Pereira ${ }^{2}$

\begin{abstract}
RESUMO
Este trabalho analisou a viabilidade econômica da produção Wean to Finish de suínos em São José do Rio Pardo nas produções independente e integrada. Foram levantados os custos fixos e variáveis anuais de manejo e manutenção de instalações, despesas administrativas e fiscais e custos da construção hipotética de uma instalação de $1.000 \mathrm{~m}^{2}$ em uma propriedade com granjas já em funcionamento. O plantel projetado foi de 1.000 animais por lote, sendo produzidos dois lotes anuais. Foram construídos dois fluxos de caixa, um para produção independente e outro para produção integrada, ambos para o período de 21 anos. O valor presente líquido (VPL) apresentou viabilidade apenas para a produção integrada, com $R \$ 634.055,44$ de lucro. A taxa interna de retorno (TIR) para tal foi de $28,40 \%$. Contudo, devido ao prejuízo encontrado para o suíno terminado, a viabilidade da produção integrada mostrou-se incerta e de alto risco ao suinocultor local.
\end{abstract}

Palavras-chave: custos de produção, produção integrada, suínos.

\section{ECONOMIC VIABILITY OF SWINE BREEDING IN WEAN TO FINISH SYSTEM IN SÃO JOSÉ DO RIO PARDO - SP}

\begin{abstract}
This work analyzed economic viability of the Wean to Finish swine production in Sao José do Rio Pardo in the independent and integrated productions. The fixed and variables annual costs of maintenance of installations, administrative and fiscal expenses and costs of hypothetical construction of installation an installation with 1000 $\mathrm{m}^{2}$ in a property with farms already in operation were done. The stock was obtained from 1000 animals per batch and were produced two annual batches. Two cash flows were done, one for independent production and another for integrated production, both for 21 years. The net present value (NPV) was only viable for integrated production, with a profit of $\mathrm{R} \$ 634,055.44$. An internal rate of return (IRR) of $28.40 \%$. However, due to the damage found for its completion, the viability of integrated production proved to be uncertain and of high risk to its local partner.
\end{abstract}

Keywords: production costs, integrated production, swines.

\footnotetext{
${ }^{1}$ Graduada em Agronegócios (FATEC Mococa/SP). Especialista em Agronegócios (PECEGE - ESALQ/USP). Mestranda em Produção Animal (Universidade Brasil).E-mail: marianezabotto.mba@gmail.com

${ }^{2}$ Graduada em Zootecnia (UFLA). Mestre em Ciências (ESALQ/USP). Doutora em Ciência Animal e Pastagens (ESALQ/USP). E-mail: rafaelazootecnia@yahoo.com.br
} 


\section{INTRODUÇÃO}

A suinocultura é uma atividade de importância econômica para a pecuária brasileira. Segundo Guimarães et. al. (2017), em 2015 o Brasil ocupou o quarto lugar na produção mundial de carne suína, com 3.519 mil toneladas produzidas. O estado de São Paulo representou cerca de $5,16 \%$ do total de abates do país (569.184 cabeças) no terceiro trimestre de 2017 (IBGE, 2018), com destaque para as regiões de Avaré, Mogi Mirim e Barretos, que produziram 81.579, 44.933 e 38.780 cabeças para abate em 2015, 2016 e 2017, respectivamente (IEA, 2018).

Sabe-se que os suinocultores enfrentam dificuldades de ordem sanitária, financeira e relacionadas ao cumprimento da legislação ambiental, dificultando muitas vezes a continuidade da atividade. Mera et. al. (2011) afirmam que o grande desafio da atividade é encontrar um destino viável para os dejetos, que têm sua produção aumentada continuamente. Assim, na tentativa de melhorar parâmetros econômicos e técnicos, surgiu o sistema Wean to Finish (WINK e GODOY, 2013). Esse sistema foi desenvolvido na década de 1990 nos Estados Unidos e tem o objetivo de alojar leitões desde o desmame até o peso de abate numa única instalação (ABCS, 2014). Segundo Medeiros (2013), o Wean to Finish é um sistema onde os suínos são desmamados e levados para uma nova instalação onde permanecem do desmame até $o$ abate.

No Brasil, o sistema Wean to Finish começou em 2006 em Santa Catarina, onde alguns produtores notaram uma superlotação nas creches e começaram a retirar precocemente os animais, destinando-os para a terminação (CONSONI, 2014). Atualmente existem 77 granjas desse sistema no país, sendo 34 no Mato Grosso do Sul, 38 em Santa Catarina e 05 no Rio Grande do Sul (ABCS, 2016).

ABCS (2015) destacam como vantagens do sistema a redução dos custos com transporte de leitões e com mão de obra, a redução de estresse e da mortalidade de suínos, menor consumo de água e produção de dejetos, assim como potencial aumento de desempenho zootécnico dos suínos e ainda uso eficiente das instalações. Massari (2014) acrescenta que o sistema diminui os custos com limpeza e desinfecção das instalações proporcionando melhor manejo sanitário, haja vista que evita a mistura de animais após a creche e mantém a homogeneidade dos lotes. Comparando o Wean to Finish com o sistema de ciclo completo, Consoni (2014) constatou menores custos de mão de obra e transportes, assim como maior ganho diário de peso dos animais.

Como desvantagens do sistema, destacam-se o alto custo das instalações pela maior área construída, alto custo com energia ou gás para aquecimento, menor número de lotes alojados por ano e fluxo grande de produção para suprir uma instalação: por volta de 1.000 animais (ABCS, 2014).

Como a produção de suínos é dependente de fatores externos, como preços das matérias-primas e preço pago pelo quilo $(\mathrm{kg})$ vivo do produto final, existem gargalos e incertezas no setor que demandam melhor gerenciamento das propriedades. Nesse cenário, além dos sistemas de produção, as formas organizacionais de trabalho dos suinocultores podem ser determinantes na diminuição de custos e aumento de rentabilidade e competitividade.

Assim, a produção integrada é caracterizada por contratos entre suinocultores e empresas processadoras que integram verticalmente várias fases do processo produtivo, como melhoramento genético, nutrição, abate, processamento e assistência técnica (ROCHA, 2006). O artigo $2^{\circ}$ da Lei número $\left(n^{\circ}\right)$ 13.288, de 16 de maio de 2016 define integração como contrato entre produtores e processadores para 
planejamento, produção, industrialização e comércio de matéria-prima, bens de consumo final, com responsabilidades previamente estabelecidas (BRASIL, 2016).

Na produção independente acontece o inverso, já que não há vínculo entre suinocultores e empresas processadoras, sendo o produtor totalmente responsável pela produção, desde a compra de insumos até a venda no mercado (ROCHA, 2006). Como a suinocultura paulista é formada quase totalmente pela produção independente, não há funcionamento de granjas especializadas em Wean to Finish (ABCS, 2016). Ao mesmo tempo, com o avanço da tecnificação e volume de abates, a produção integrada hoje, além da região Sul, está presente em pontos isolados da região Sudeste, principalmente nos estados de São Paulo e Minas Gerais. Este estudo teve o objetivo de apresentar uma análise de viabilidade econômica da implementação do sistema Wean to Finish em sistema de integração e independente de produção de suínos na cidade de São José do Rio Pardo, localizado em São Paulo.

\section{METODOLOGIA}

Para o estudo de viabilidade econômica foi feita uma simulação de construção de um galpão Wean to Finish com capacidade de alojamento de 02 lotes anuais de 1.000 suínos, que seriam distribuídos em 40 baias de 25 animais em cada. A propriedade já produziria suínos e já teria os setores de reprodução e maternidade implantados e em funcionamento. O escoamento de dejetos, o descarte de embalagens e outros materiais e a armazenagem de ração e outros insumos foram desconsiderados nos cálculos, pensando que esses itens já existiriam na propriedade e já atenderiam a produção antes da construção desse projeto.

Nesse estudo foram levantados os custos fixos e variáveis de implantação e manutenção do sistema, que serviram de base para a construção de 02 fluxos de caixa para avaliação econômica da implementação do sistema Wean to Finish em produção integrada e independente. Os custos foram estimados considerando uma produção independente, onde o suinocultor assumiria compromissos de construção do galpão, compra de equipamentos, compra de insumos de produção, taxas eventuais de gastos e financiamento. Esses custos foram utilizados também para a produção integrada, sendo desconsiderados no fluxo de caixa os custos que não fizeram parte das obrigações de um produtor integrado.

Os fluxos de caixa foram construídos para um projeto de 21 anos, onde a receita operacional foi estimada a partir do ano 01 e os investimentos em instalações e equipamentos, custos de depreciação e do Fundo de Assistência ao Trabalhador Rural (FUNRURAL) foram calculados com base em 2018, sem considerar reajustes futuros. O Imposto de Renda da Pessoa Jurídica (IRPJ) e a Contribuição Social sobre o Lucro Líquido (CSLL) incidiram sobre o lucro tributável.

Nos fluxos, os custos fixos e variáveis foram somados e resultaram no custo total, que foi subtraído da receita operacional e gerou o lucro operacional bruto. Deste valor foram descontados a depreciação, o FUNRURAL e o custo de oportunidade da terra e obteve-se o lucro tributável. Desse total ainda foram subtraídos o IRPJ e a CSLL e, sob o lucro líquido resultante, foram somados novamente a depreciação, o FUNRURAL e o custo de oportunidade da terra para obter o resultado dos fluxos de caixa. De acordo com Meyer \& Paixão (2018), a subtração de depreciação e impostos é útil para cálculo dos tributos, não representando um gasto efetivamente realizado pela empresa. A soma desses itens no lucro líquido oferece o saldo real do fluxo de caixa no ano em questão.

Segundo Rocha Junior et. al. (2012), nos contratos de integração do tipo parceria, mais comuns na fase de terminação, o produtor é dono das instalações, equipamentos e da mão de obra, sendo a integradora responsável pelos custos de 
assistência técnica, medicamentos, vacinas, material sanitário e demais insumos necessários. Assim, o fluxo de caixa da produção integrada desse estudo não contabilizou os custos de alimentação, material de limpeza e desinfecção, fretes e eventuais.

\subsection{CARACTERIZAÇÃO DO LOCAL}

O município de São José do Rio Pardo ocupa uma área de $419.684 \mathrm{~km}^{2} \mathrm{e}$ está localizada na região nordeste paulista, latitude 2135'44" sul, longitude 4653'19" oeste e altitude média de 676 metros (IBGE, 2018). A temperatura média anual varia de $15^{\circ} \mathrm{C}$ a $28^{\circ} \mathrm{C}$, sendo maio, junho e julho os meses mais frios do ano (CEPAGRI; MAPA/INMET, 2018).

A agropecuária da mesorregião de Campinas, a qual pertence a cidade objeto desse estudo, é caracterizada por pequenas propriedades, em sua maioria com produções de hortifrúti, que tratam a suinocultura como uma alternativa de renda (ABCS, 2016). A economia do município é baseada na agricultura, especialmente pela presença da multinacional Nestlé, que tradicionalmente compra grande parte da produção olerícola dos produtores locais. Em 2016, a área ocupada com culturas permanentes e temporárias somaram 6.205 hectares (ha). A pecuária também se destaca na economia municipal, especialmente a avicultura, com 3.000.000 unidades produzidas em 2016. Neste mesmo ano foram contabilizadas as produções de 49.500 bovinos, 15.900 suínos, 1.380 ovinos, 570 equinos e 153 bubalinos (IBGE, 2018). A suinocultura, portanto, representa o terceiro lugar na pecuária local.

\subsection{ESTIMATIVAS DE CUSTOS}

Os custos fixos dos projetos seguem na Tabela 1.

Tabela 1 - Custos fixos para suinocultor independente e integrado

\begin{tabular}{|c|c|c|c|c|c|}
\hline Componente & $\begin{array}{l}\text { Quant. } \\
\text { anual }\end{array}$ & $\begin{array}{r}\text { Preço } \\
\text { unit. }(\mathbf{R} \$)\end{array}$ & $\begin{array}{r}\text { Custo anual } \\
(\mathbf{R} \$)\end{array}$ & $\begin{array}{c}\text { Quant. } \\
\text { total para } \\
\text { o projeto }\end{array}$ & $\begin{array}{l}\text { Custo total } \\
\text { para o projeto }\end{array}$ \\
\hline Instalações (Un.) & 1 & $358.100,00$ & $358.100,00$ & 1 & $716.200,00$ \\
\hline $\begin{array}{l}\text { Sist. de alimentação } \\
\text { (Un.) }\end{array}$ & 1 & $101.932,61$ & $101.932,61$ & 2 & $203.865,22$ \\
\hline $\begin{array}{l}\text { Sist. de cortinas } \\
\text { laterais (Un.) }\end{array}$ & 1 & $10.105,20$ & $10.105,20$ & 2 & $20.210,40$ \\
\hline Sistema de forro (Un.) & 1 & $14.214,27$ & $14.214,27$ & 2 & $28.428,54$ \\
\hline $\begin{array}{l}\text { Sist. de aquecimento } \\
\text { (Un.) }\end{array}$ & 1 & $17.717,28$ & $17.717,28$ & 2 & $35.434,56$ \\
\hline Custo da terra $(\mathrm{Ha})$ & 0,1 & $21.666,67$ & $2.166,67$ & 0,1 & $2.166,67$ \\
\hline $\begin{array}{l}\text { Financiamento com } \\
\text { juros (Un.) }\end{array}$ & 1 & $740.611,90$ & $740.611,90$ & 1 & $740.611,90$ \\
\hline TOTAIS & & & $1.244 .847,93$ & & $1.746 .917,29$ \\
\hline
\end{tabular}

Fonte: Dados da Pesquisa

O projeto e a execução da obra da instalação foram orçados em uma empresa local de engenharia civil, que considerou a construção de 01 galpão Wean to Finish de $1.000 \mathrm{~m}^{2}$ para elaboração do projeto detalhado em software de engenharia AutoCad® ${ }^{\circledR}$, serviços de medições a campo, mão-de-obra para construção e fornecimento de Anotação de Responsabilidade Técnica (ATR) de engenheiro 
responsável, fabricação e montagem de estruturas metálicas e telhado de cerâmica, construção de muros de alvenaria, construção de pé direito e estimativas de despesas com materiais de construção. $O$ orçamento de todos os equipamentos necessários para a automação dos sistemas de alimentação, cortinas laterais e forro foi obtido de empresa fabricante especializada em produtos para Wean to Finish localizada no estado de São Paulo. O sistema de aquecimento projetado foi constituído de 02 aquecedores a gás GLP, orçados por empresa distribuidora de importados localizada no estado do Rio de Janeiro.

Foi feita uma simulação do custo total das instalações e equipamentos através de financiamento pelo programa Inovagro, do Banco Nacional de Desenvolvimento (BNDS), cuja taxa de juros dada foi $6,5 \%$ ao ano, com prazo de pagamento de 10 anos e carência de 03 anos.

Como o terreno ocupado pelo galpão já faria parte da propriedade, o custo do mesmo foi levantado a fim de compor o custo de oportunidade de uso alternativo da terra. Para o cálculo da área, foi estabelecido o espaço de $1 \mathrm{~m}^{2}$ para cada suíno com peso médio igual ou superior a $110 \mathrm{~kg}$, conforme o decreto-lei $n^{\circ} 135 / 2003$ (BRASIL, 2003). Assim, obteve-se uma área de $1.000 \mathrm{~m}^{2}$. O custo da terra ocupada pela instalação foi calculado com base na classificação de valores de terra nua do Instituto Agronômico de Campinas (IAC), considerando o valor médio do ha de terra nua com aptidão regular na região de São José do Rio Pardo/SP. Foi feita a conversão da área total da instalação de $\mathrm{m}^{2}$ para ha e multiplicou-se o resultado pelo valor do ha dado pelo IEA (2018). Os custos variáveis da produção independente e integrada seguem nas Tabelas 2 e 3.

Tabela 2 - Custos variáveis para suinocultor independente

\begin{tabular}{|c|c|c|c|c|c|c|}
\hline Componente & & $\begin{array}{l}\text { Quant. } \\
\text { anual }\end{array}$ & $\begin{array}{r}\text { Preço unit. } \\
(\mathbf{R} \$)\end{array}$ & $\begin{array}{r}\text { Custo anual } \\
(\mathbf{R} \$)\end{array}$ & $\begin{array}{l}\text { Quant. } \\
\text { total para } \\
\text { o projeto }\end{array}$ & $\begin{array}{r}\text { Custo total } \\
\text { para o projeto } \\
(\mathbf{R} \$)\end{array}$ \\
\hline $\begin{array}{l}\text { Licenças } \\
\text { ambientais }\end{array}$ & Un. & 1 & $12.850,00$ & $12.850,00$ & 6 & $77.100,00$ \\
\hline Alimentação & sacas & $\begin{array}{r}39.06 \\
2 \\
\end{array}$ & 29,3946 & $1.148 .212,00$ & 78.124 & $2.296 .424,00$ \\
\hline Mão de obra & Meses & 12 & $2.390,74$ & $28.688,88$ & 252 & $602.466,48$ \\
\hline Frete & Sc & $\begin{array}{r}5554 \\
7 \\
\end{array}$ & 2,00 & $111.094,00$ & 1.110 .940 & $2.221 .880,00$ \\
\hline $\begin{array}{l}\text { Energia } \\
\text { elétrica }\end{array}$ & $\mathrm{Kw} / \mathrm{h}$ & $\begin{array}{r}3600 \\
0 \\
\end{array}$ & 0,1835 & $6.606,00$ & 756.000 & $138.726,00$ \\
\hline Aquecimento & Hrs & 2184 & 49,47 & $108.042,48$ & 43.680 & $2.160 .849,60$ \\
\hline $\begin{array}{l}\text { Limpeza e } \\
\text { desinfecção }\end{array}$ & Anos & 1 & $163.320,00$ & $163.320,00$ & 21 & $3.429 .720,00$ \\
\hline FGTS & Anos & 1 & $2.429,10$ & $2.429,10$ & 21 & $51.011,10$ \\
\hline Depreciação & Anos & 1 & $22.769,59$ & $22.769,59$ & 21 & $478.161,39$ \\
\hline TOTAIS & & & & $1.604 .012,05$ & & $11.456 .338,57$ \\
\hline
\end{tabular}

Fonte: Dados da Pesquisa 
Tabela 3 - Custos variáveis para suinocultor integrado

\begin{tabular}{lcrrrrr}
\hline Componente & $\begin{array}{r}\text { Quant. } \\
\text { anual }\end{array}$ & $\begin{array}{r}\text { Preço } \\
\text { unit. (R\$) }\end{array}$ & $\begin{array}{r}\text { Custo } \\
\text { anual (R\$) }\end{array}$ & $\begin{array}{r}\text { Quant. } \\
\text { total para o } \\
\text { projeto }\end{array}$ & $\begin{array}{r}\text { Custo total } \\
\text { para o } \\
\text { projeto (R\$) }\end{array}$ \\
\hline $\begin{array}{l}\text { Licenças } \\
\text { ambientais }\end{array}$ & Un. & 1 & $12.850,00$ & $12.850,00$ & 6 & $77.100,00$ \\
\hline Mão de obra & $\begin{array}{c}\text { Mese } \\
\mathrm{S}\end{array}$ & 12 & $2.390,74$ & $28.688,88$ & 252 & $602.466,48$ \\
\hline Energia elétrica & $\mathrm{Kw} / \mathrm{h}$ & 36000 & 0,1835 & $6.606,00$ & 756.000 & $138.726,00$ \\
\hline Aquecimento & $\mathrm{Hrs}$ & 2184 & 49,47 & $108.042,48$ & 43.680 & $2.160 .849,60$ \\
\hline FGTS & Anos & 1 & $2.429,10$ & $2.429,10$ & 21 & $51.011,10$ \\
\hline Depreciação & Anos & 1 & $22.769,59$ & $22.769,59$ & 21 & $478.161,39$ \\
\hline TOTAIS & & & & $\mathbf{1 8 1 . 3 8 6 , 0 5}$ & & $\mathbf{3 . 5 0 8 . 3 1 4 , 5 7}$ \\
\hline
\end{tabular}

Fonte: Dados da Pesquisa

O valor da UFESP ${ }^{3}$ dado para a atividade suinícola no estado de São Paulo foi de 500. Assim, para a obtenção do custo do licenciamento ambiental, esse valor foi multiplicado pelo preço unitário de $R \$ 25,70$, dado pela Secretaria da Fazenda do Estado de São Paulo para o ano de 2018 para emissão das licenças prévia, de instalação e de operação e por renovação da licença de operação a cada 05 anos.

Para estimar o custo com alimentação, foram considerados os valores de consumo diário propostos por Rostagno et. al. (2017) para cada fase de produção de suínos machos cadastrados de alto potencial genético com desempenho médiosuperior, adaptando a classificação de idade e peso às três fases de produção que compõem o Wean to Finish. As médias aritméticas dos consumos diários de cada fase foram relacionadas com a quantidade de lotes por ano, o período/dias de alojamento dos lotes e a quantidade de animais por lote considerando taxa média de $2 \%$ de mortalidade para o sistema, baseado em Morés (2014). Foram orçados 03 tipos de rações de acordo com a fase de desenvolvimento dos animais. Assim, o consumo de ração por lote foi estimado pela multiplicação do consumo unitário médio por 980 animais e posteriormente por 140 dias de alojamento de cada lote. Esse resultado, multiplicado por 02 lotes anuais, resultou no consumo unitário médio por ano de cada fase que, dividido pelo peso das sacas de ração compradas de terceiros, gerou a quantidade de sacas a comprar no ano. Essa quantidade, multiplicada pelo preço unitário das sacas resultaram no custo total de ração para o sistema.

O custo com mão de obra levou em consideração o trabalho familiar, onde os envolvidos receberiam um salário mensal com os devidos encargos de contratação por carteira assinada, conforme legislação.

A estimativa de gasto anual de frete com ração partiu do custo de $R \$ 2,00$ por saca transportada, conforme estabelecido pelo fornecedor. O transporte de equipamentos e de materiais de limpeza e desinfecção não foram contabilizados, já que ficariam sob responsabilidade das empresas fornecedoras.

A despesa anual com energia elétrica teve como referência a recomendação de Martins et. al. (2012) para Kw/h consumidos na fase de terminação em granjas de Minas Gerais, local mais próximo da cidade objeto desse estudo. Assim, o consumo

\footnotetext{
${ }^{3}$ Unidade Fiscal do Estado de São Paulo: índice anual divulgado pela Secretaria Estadual da Fazenda para cálculo do preço do licenciamento ambiental de todos os tipos de empreendimentos (ANA/CETESB, 2018).
} 
anual foi multiplicado pelo preço unitário do quilowatt-hora $(\mathrm{kw} / \mathrm{h})$ obtido na concessionária de energia elétrica local, correspondente à tarifa para zona rural.

O cálculo da despesa anual com limpeza e desinfecção considerou o uso de produtos químicos apenas no término de cada lote, quando aconteceria o vazio sanitário. Os produtos para a limpeza e desinfeção orçados foram desinfetante, detergente, inseticida e raticida, em uma empresa fabricante localizada dentro do estado de São Paulo. A dosagem média de desinfetante utilizada para o cálculo do custo foi de $300 \mathrm{ml}$ por $\mathrm{m}^{2}$, conforme recomendação de ABCS (2014). O mesmo se aplicou para o cálculo do custo do detergente. Assim, as dosagens foram multiplicadas por $1.000 \mathrm{~m}^{2}$ de área do galpão e geraram uma quantidade de uso estimada em $300.000 \mathrm{ml}$ por lote. As quantidades de inseticida e raticida foram convertidas de gramas para ml e seguiram a mesma recomendação. Assim, foi considerado que cada pacote de inseticida conteria 1,667 gramas $/ \mathrm{ml}$ e cada pacote de raticida conteria 3,334 gramas/ml. Multiplicaram-se então esses resultados por $300.000 \mathrm{ml}$ calculados para cada lote, o que resultou em necessidade de 500.100 gramas de inseticida e 1.000.200 gramas de raticida estimados por lote. Para determinar o volume necessário a comprar, as quantidades de desinfetante e detergente foram convertidas de $\mathrm{ml}$ para litros e os resultados foram divididos pela unidade de medida informada pelo fornecedor. As quantidades de inseticida e raticida não necessitaram de conversão, sendo apenas divididas pela unidade de medida do fornecedor. O resultado dessas divisões gerou o volume comprar, que foi multiplicado pelo preço unitário de cada produto.

O total recolhido anualmente para o Fundo de Garantia do Tempo de Serviço (FGTS) foi calculado com base na porcentagem de $8 \%$ sobre os salários brutos mensais de um capataz e um mensalista.

A taxa de eventuais teve o objetivo de cobrir possíveis despesas extras além das já levantadas. Nesse trabalho foi utilizado 3\% para a taxa de eventuais, de acordo com recomendação de Meyer e Paixão (2018). Esse percentual incidiu sobre o total de custos fixos e variáveis. Nos custos fixos, a taxa teve a função de custear gastos com mão de obra terceirizada e peças para manutenção e conservação de instalações, equipamentos e terreno. Nos custos variáveis, a taxa cobriu despesas extras referentes a gastos veterinários, medicamentos, vacinas, treinamentos e reajustes de preços de insumos.

A depreciação foi calculada pelo método linear, dividindo a diferença entre valor inicial e valor residual pela vida útil dos itens, dada pelos fornecedores, conforme equação abaixo, proposta por Meyer e Paixão (2018):

$$
D=\frac{(V I-V R)}{v u}
$$

onde D: depreciação; VI: valor inicial do equipamento; VR: valor residual do equipamento; e vu: vida útil do equipamento.

O inciso I do artigo 25 da lei no 13.606/18, de 09/01/2018 instituiu a alíquota de $1,7 \%$, referente ao Funrural ${ }^{4}$ para produtor rural pessoa jurídica. Essa lei reduziu a alíquota para pessoa jurídica, sancionadas anteriormente pela lei no 8.870 , de 5 de abril de 1994, em seu artigo 25. Assim, para efeito do cálculo de lucro tributável nos fluxos de caixa, a taxa de $1,7 \%$ foi descontada do lucro operacional bruto e, para considerar o lucro econômico no saldo final dos fluxos, foi adicionada novamente.

\footnotetext{
${ }^{4}$ Imposto de contribuição previdenciária incidente sobre a receita bruta das vendas de produção agropecuária (BRASIL, 2018).
} 
Para a determinação da receita operacional da produção independente, o preço do kg do suíno vivo pago ao suinocultor pelo mercado no estado de São Paulo foi estimado para 20 anos futuros através da ferramenta planilha de previsão do Microsoft Excel® 2016, que processou uma série histórica mensal de preços médios de 2010 a abril de 2018, adquirida da base de dados do Centro de Estudos Avançados em Economia Aplicada (CEPEA).

A ferramenta submeteu a série de dados ao método de suavização exponencial na modelagem de previsão Hold-Winters e gerou uma projeção futura do preço unitário do $\mathrm{kg}$ do suíno vivo com intervalo de confiança de 99,99\%. Desses resultados mensais foram extraídas as médias aritméticas, estimando assim o preço anual futuro do $\mathrm{kg}$ do suíno. De posse desses dados, o cálculo das receitas por suíno foi feito pela multiplicação dos preços unitários pelo peso final de abate de $105 \mathrm{~kg}$, já considerando o rendimento de carcaça de $84 \%$, relativo ao peso da carcaça quente (ABCS, 2016). O cálculo das receitas por lote foi feito pela multiplicação das receitas unitárias por 980 animais (considerando as perdas no plantel por mortalidade, a taxa de $2,00 \%$ ). Por fim, as receitas anuais foram estimadas pela multiplicação das receitas dos lotes por 02 lotes anuais. O preço unitário médio estimado para 20 anos futuros de $R \$ 5,37$ foi calculado pela média aritmética de todos os preços unitários por kg vivo estimados. Esse resultado foi utilizado nas discussões dos resultados desse trabalho. As estimativas de receita da produção independente seguem na Tabela 4. 
Tabela 4 - Estimativas de preços e receitas da produção independente

\begin{tabular}{|c|c|c|c|c|}
\hline $\begin{array}{c}\text { Anos } \\
\text { (Fluxo de Caixa) }\end{array}$ & $\begin{array}{r}\text { Preço } \\
\text { Unitário } \\
(\mathrm{R} \$ / \mathrm{kg} \\
\text { vivo) }\end{array}$ & $\begin{array}{r}\text { Receita } \\
(\mathbf{R} \$ / \text { suíno })\end{array}$ & $\begin{array}{r}\text { Receita } \\
\text { (R\$/lote) }\end{array}$ & $\begin{array}{r}\text { Receita } \\
\text { (R\$/ano) }\end{array}$ \\
\hline 1 & 3,77 & 395,85 & $387.933,00$ & $775.866,00$ \\
\hline 2 & 3,93 & 412,65 & $404.397,00$ & $808.794,00$ \\
\hline 3 & 4,10 & 430,50 & $421.890,00$ & $843.780,00$ \\
\hline 4 & 4,27 & 448,35 & $439.383,00$ & $878.766,00$ \\
\hline 5 & 4,44 & 466,20 & $456.876,00$ & $913.752,00$ \\
\hline 6 & 4,61 & 484,05 & $474.369,00$ & $948.738,00$ \\
\hline 7 & 4,78 & 501,90 & $491.862,00$ & $983.724,00$ \\
\hline 8 & 4,95 & 519,75 & $509.355,00$ & $1.018 .710,00$ \\
\hline 9 & 5,12 & 537,60 & $526.848,00$ & $1.053 .696,00$ \\
\hline 10 & 5,29 & 555,45 & $544.341,00$ & $1.088 .682,00$ \\
\hline 11 & 5,46 & 573,30 & $561.834,00$ & $1.123 .668,00$ \\
\hline 12 & 5,63 & 591,15 & $579.327,00$ & $1.158 .654,00$ \\
\hline 13 & 5,79 & 607,95 & $595.791,00$ & $1.191 .582,00$ \\
\hline 14 & 5,96 & 625,80 & $613.284,00$ & $1.226 .568,00$ \\
\hline 15 & 6,13 & 643,65 & $630.777,00$ & $1.261 .554,00$ \\
\hline 16 & 6,30 & 661,50 & $648.270,00$ & $1.296 .540,00$ \\
\hline 17 & 6,47 & 679,35 & $665.763,00$ & $1.331 .526,00$ \\
\hline 18 & 6,64 & 697,20 & $683.256,00$ & $1.366 .512,00$ \\
\hline 19 & 6,81 & 715,05 & $700.749,00$ & $1.401 .498,00$ \\
\hline 20 & 7,00 & 735,00 & $720.300,00$ & $1.440 .600,00$ \\
\hline
\end{tabular}

Fonte: Dados da Pesquisa

A receita da produção integrada foi mais complexa de se estimar, visto que as integradoras estabelecem diferentes critérios para remuneração dos produtores, muitas vezes baseadas em metodologias próprias de índices de produtividade e porcentagem mínima de pagamento, o que garante a elas o controle da produção (COSER, 2010). Miele e Waquil (2006) afirmam que, para a bonificação, essas empresas monitoram critérios como biosseguridade, separação por sexo, gestão da granja e adesão a programas de melhoramento genético, de nutrição e de pacotes veterinários.

Porém, devido às discussões e discordâncias entre os agentes envolvidos nos contratos, a lei $n^{\circ} 13.288$ normatizou a integração e pretende definir um preço de referência para a remuneração do integrado. Essa definição depende das metodologias de cálculo apresentadas por agentes do setor que desde então têm se reunido para discutir sobre o assunto. Como até a conclusão desse estudo não houve 
um consenso e consequente divulgação de metodologia, a receita operacional da produção integrada desse estudo foi determinada com a estimativa do preço do kg do suíno vivo pago ao suinocultor pela integradora. Esses preços foram estimados para 20 anos futuros através da ferramenta planilha de previsão do Microsoft Exce|ß 2016. A série histórica de preços médios processada, de 2007 a abril de 2018, foi adquirida na base de dados da Associação Catarinense de Criadores de Suínos (ACCS). Essa ferramenta também usou o método de suavização exponencial com a modelagem Hold-Winters para estimar preços futuros. Apesar de apresentar dados da realidade de outro Estado, este órgão é um dos poucos a disponibilizar preços internos das integradoras, além de representar o estado com a maior produção integrada do país, onde cerca de dois terços dos abates dos estabelecimentos derivam de contratos com suinocultores (COSER, 2010), o que serve de base para estudos em outros locais. Assim, foi gerada uma projeção futura do preço unitário do $\mathrm{kg}$ do suíno vivo com intervalo de confiança de 99,99\%.

Desses resultados mensais foram extraídas as médias aritméticas, estimando assim o preço anual futuro do kg do suíno para produção integrada. A partir disso, a receita operacional foi estimada considerando cota base ${ }^{5}$ de $16,5 \%$, conforme levantamento de Coser (2010) aplicada na fórmula proposta por Miele e Waquil (2006) para remuneração de unidades de terminação ${ }^{6}$. Os percentuais de produtividade foram desconsiderados, a fim de expressar o mínimo recebível pelo integrado. Assim, a receita estimada por lote foi multiplicada por 02 lotes e gerou a receita anual. $\mathrm{O}$ preço unitário médio estimado para 20 anos futuros de $R \$ 4,54$ foi calculado pela média aritmética de todos os preços unitários por $\mathrm{kg}$ vivo estimados. Esse resultado foi utilizado nas discussões dos resultados desse trabalho.

As estimativas de receita da produção integrada seguem na Tabela 5.

\footnotetext{
5 Remuneração mínima estabelecida pelas integradoras para pagamento dos integrados excluídos os resultados de produtividade (COSER, 2010)

${ }^{6}$ Remuneração $=\%$ Cota Base $X$ número de suínos entregues $X$ peso médio $X$ preço médio do kg vivo pago pela integradora
} 
Tabela 5 - Estimativas de preços e receitas da produção integrada

\begin{tabular}{crrrr}
\hline $\begin{array}{c}\text { Anos } \\
\text { (Fluxo de Caixa) }\end{array}$ & $\begin{array}{r}\text { Preço Unitário } \\
\text { (R\$/kg vivo) }\end{array}$ & $\begin{array}{r}\text { Receita } \\
\text { (R\$/suíno) }\end{array}$ & $\begin{array}{r}\text { Receita } \\
\text { (R\$/lote) }\end{array}$ & $\begin{array}{r}\text { Receita } \\
\text { (R\$/ano) }\end{array}$ \\
\hline 1 & 3,28 & 56,83 & $55.693,40$ & $111.386,80$ \\
\hline 2 & 3,42 & 59,25 & $58.065,00$ & $116.130,00$ \\
\hline 3 & 3,55 & 61,50 & $60.270,00$ & $120.540,00$ \\
\hline 4 & 3,68 & 63,76 & $62.484,80$ & $124.969,60$ \\
\hline 5 & 3,82 & 66,18 & $64.856,40$ & $129.712,80$ \\
\hline 6 & 3,95 & 68,43 & $67.061,40$ & $134.122,80$ \\
\hline 7 & 4,08 & 70,68 & $69.266,40$ & $138.532,80$ \\
\hline 8 & 4,21 & 72,93 & $71.471,40$ & $142.942,80$ \\
\hline 9 & 4,35 & 75,36 & $73.852,80$ & $147.705,60$ \\
\hline 10 & 4,48 & 77,62 & $76.067,60$ & $152.135,20$ \\
\hline 11 & 4,61 & 79,87 & $78.272,60$ & $156.545,20$ \\
\hline 12 & 4,74 & 82,12 & $80.477,60$ & $160.955,20$ \\
\hline 13 & 4,88 & 84,55 & $82.859,00$ & $165.718,00$ \\
\hline 14 & 5,01 & 86,80 & $85.064,00$ & $170.128,00$ \\
\hline 15 & 5,14 & 89,05 & $87.269,00$ & $174.538,00$ \\
\hline 16 & 5,28 & 91,48 & $89.650,40$ & $179.300,80$ \\
\hline 17 & 5,41 & 93,73 & $91.855,40$ & $183.710,80$ \\
\hline 18 & 5,54 & 95,98 & $94.060,40$ & $188.120,80$ \\
\hline 19 & 5,67 & 98,23 & $96.265,40$ & $192.530,80$ \\
\hline 20 & 5,81 & 100,66 & $98.646,80$ & $197.293,60$ \\
\hline
\end{tabular}

Fonte: Dados da Pesquisa

Foi calculado o Valor Presente Líquido (VPL), conforme fórmula abaixo, de Silva e Fontes (2005):

$$
V P L=\sum_{j=0}^{n} R_{j}(1+i)^{-j}-\sum_{j=0}^{n} C_{j}(1+i)^{-j}
$$

Onde $\mathrm{Rj}=$ valor atual das receitas; $\mathrm{C}$ = valor atual dos custos; $\mathrm{i}=$ taxa de juros; $\mathrm{j}$ = período em que as receitas ou os custos ocorrem; e $n=$ número de períodos ou duração do projeto

Para o VPL, taxa mínima de atratividade (TMA) selecionada foi o custo de oportunidade de uso da terra que, convertido para porcentagem, ficou em $8,14 \%$. Essa TMA nominal foi transformada em TMA real, descontando a inflação de 1,86\% para 
junho de 2018, dada pelo Índice Geral de Preços (FGV, 2018) e foi utilizada para cálculo dos indicadores a $6,16 \%$, conforme fórmula proposta por Meyer e Paixão (2018):

$$
\text { TMA real }=\frac{(1+\text { taxa nominal })}{(1+\text { inflação })-1}
$$

A taxa interna de retorno (TIR) foi calculada para todos os períodos (anos). Segundo Kassai (1996), a TIR representa a taxa de desconto que iguala o fluxo de caixa em um momento, tornando-o zerado. A fórmula, segundo o autor, segue abaixo:

$$
N P V \frac{=F C_{0}+F C_{1}+F C_{2}+F C_{3}+F C_{n}}{(1+T I R) \cdot 0(1+T I R) \cdot 1(1+T I R) \cdot 2(1+T I R) \cdot 3(1+T I R) \cdot n}
$$

Onde, onde, FC: é o fluxo de caixa esperado; NPV: é 0.

Para o cálculo do payback simples, foram confeccionados fluxos de caixa acumulados e para o payback descontado, fluxos de caixa acumulados descontados.

\section{RESULTADOS E DISCUSSÃO}

Para a produção independente de suínos no sistema Wean to Finish, o VPL apresentou valor negativo de $R \$ 20.479 .973,79$, o que mostrou inviabilidade do projeto. Nesse caso, a TIR e o payback não foram calculados, já que o VPL negativo não teve a possibilidade de se tornar positivo dentro do horizonte de tempo do fluxo de caixa, independente dos resultados da TIR e do payback. Nesse caso, os resultados desses indicadores não seriam apropriados e relevantes para a decisão de implementar o projeto.

O principal motivo para o resultado negativo dos indicadores foi o alto custo da alimentação. Sabe-se que na suinocultura tradicional, a alimentação é responsável pela maior parcela dos custos de produção, variando de 58 a 76\% (MAPA/CONAB, 2018). Esse resultado se confirmou na análise econômica deste estudo para produção independente de suínos, onde a alimentação representou $81,68 \%$ dos custos variáveis e $R \$ 9,19$ na composição do custo de produção por kg vivo de suíno. Nessa mesma composição de custos, a alimentação seria o único item não remunerado pelo preço unitário médio de mercado de $\mathrm{R} \$ 5,37$ para o kg vivo de suíno, estimado para 20 anos futuros.

Embora tenha ocorrido uma redução nos custos totais $(0,50 \%)$ nos anos em que não houve renovação do licenciamento ambiental, esse resultado não foi capaz de tornar o VPL positivo do Wean to Finish para produção independente. A partir do ano 03 do fluxo de caixa, o custo fixo anual aumentou em $491,71 \%$ com o pagamento das parcelas do financiamento. No ano 10 houveram novos reinvestimentos referentes a aquisição de máquinas e equipamentos novos.

O fluxo de caixa da produção independente segue na Figura 1. 
Figura 1 - Fluxo de caixa da produção independente

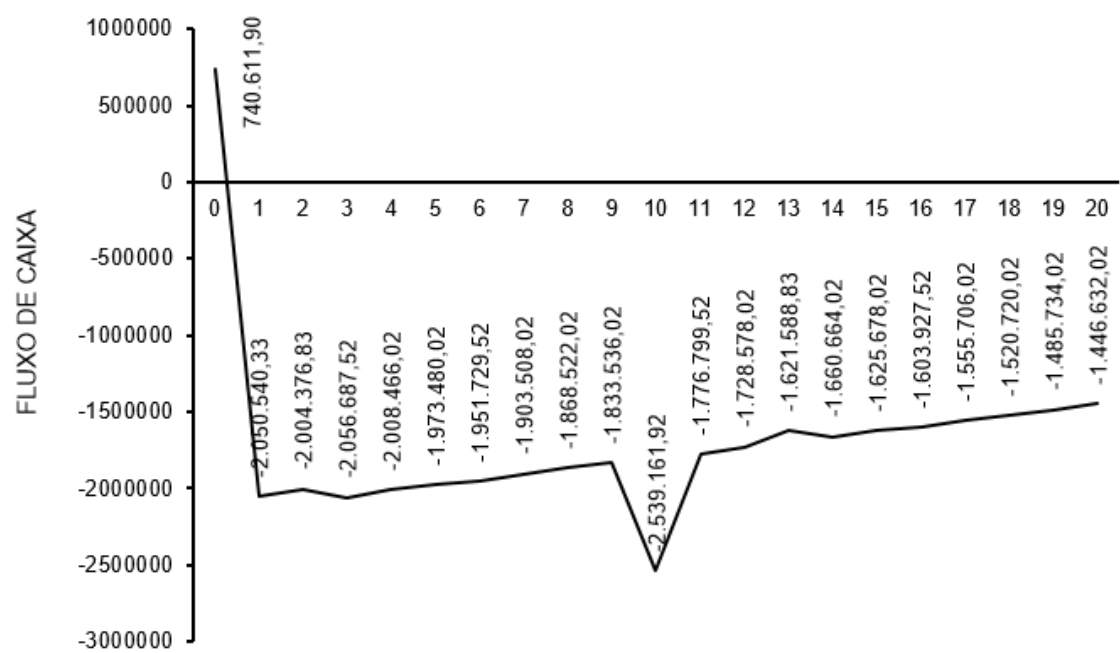

ANOS

Fonte: Dados da Pesquisa

O custo unitário para produção de $01 \mathrm{~kg}$ vivo de suíno terminado foi de $R \$$ 11,87 na produção independente. Se comparado ao preço unitário de mercado de $R \$$ 5,37 por kg vivo de suíno, daria um prejuízo de $\mathrm{R} \$ 6,50$ por kg vivo produzido. Para efeito de comparação, se ao custo de produção Wean to Finish de $\mathrm{R} \$ 3,50$ por kg vivo produzido, descrito por Consoni (2014), fossem somados U\$ 0,60 centavos de dólar extra conforme descrito por ABCS (2014), ainda assim o custo de produção seria menor que o custo encontrado nesse trabalho para a produção independente.

O custo unitário de produção de um suíno terminado no sistema independente resultou em $\mathrm{R} \$ 1.424,43$. A média das receitas operacionais gerou lucro bruto de $R \$ 564,11$ por suíno, que demonstra prejuízo médio da atividade no sistema independente de cerca de $\mathrm{R} \$ 860,32$ por animal. O estudo de Rocha (2006) mostrou probabilidade de lucro de $67,50 \%$. Talvez esses resultados estejam relacionados à região geográfica, já que o autor realizou a pesquisa em Santa Catarina e Minas Gerais.

Os resumos dos custos de produção seguem na Tabela 6.

Tabela 6 - Custo de produção de suíno no sistema independente

\begin{tabular}{lcc}
\hline Custos & Custo (R\$/kg) & Participação (\%) \\
\hline COE (custos variáveis) & 11,24 & 94,69 \\
\hline COT (COE + depreciação) & 11,35 & 95,61 \\
\hline CT (COT + custo de oportunidade) & $\mathbf{1 1 , 3 6}$ & \\
\hline
\end{tabular}

Fonte: Dados da Pesquisa 
O projeto de construção e funcionamento do sistema Wean to Finish em São José do Rio Pardo não seria interessante para o suinocultor independente, uma vez que os custos totais de produção seriam elevados a ponto de não remunerar o capital investido. Mesmo o estado de São Paulo sendo tradicional na produção independente, o modelo de produção proposto necessita de maiores possibilidades de redução de custos.

Para a produção integrada de suínos no sistema Wean to Finish, o VLP apresentou valor positivo de $\mathrm{R} \$ 634.055,44$, o que mostrou viabilidade do projeto. A TIR encontrada foi de $28,40 \%$, que confirma a viabilidade, já que essa porcentagem foi maior que a TMA de $6,16 \%$. Isso permitiu concluir que o retorno do investimento ao final do horizonte de tempo do fluxo de caixa foi maior que a taxa de remuneração esperada pelo suinocultor para o mesmo período. Não houve período de payback, já que o investimento inicial não foi pago do horizonte de tempo do fluxo de caixa. Além disso, a partir do ano 10, houve reinvestimento em máquinas e equipamentos novos, o que negativou o saldo do fluxo de caixa por mais tempo.

Os resultados de Gollo et. al. (2017) divergem desse estudo, pois foi encontrado VPL negativo de $\mathrm{R} \$ 48.446,37$ na produção integrada de suínos. Isso pode ser decorrente da competição da suinocultura com outra fonte de renda, o que foi constatado no estudo desses autores, onde a principal fonte de renda da propriedade estudada era a bovinocultura de leite.

O principal motivo dos resultados positivos no sistema Wean to Finish para produção integrada foi a diminuição dos custos de produção, já que a empresa integradora se responsabilizaria pelos custos variáveis de alimentação, material de limpeza e desinfecção, fretes e eventuais. Com o compartilhamento de custos entre integradora e integrado, as despesas com aquecimento e a mão-de-obra representaram os itens de maior despesa variável para o suinocultor, com $68,12 \%$ e $18,09 \%$ de participação nos custos variáveis, respectivamente. Talamini et. al. (2006), Kruger et. al. (2017) e Gollo et. al. (2017) tiveram conclusões semelhantes ao encontrarem maior custo com mão-de-obra na produção integrada de suínos, sendo esse item responsável por 59,66\%, 5,62\% e 75,97\% dos custos variáveis, respectivamente.

O financiamento e o licenciamento ambiental tiveram influência direta no lucro líquido do projeto, de forma que, com o começo do pagamento do financiamento e a renovação do licenciamento ocorrendo simultaneamente no ano 03 do fluxo de caixa, houve prejuízo para este ano e para os anos seguintes. A partir do ano 12 houve recuperação do lucro devido ao fim do pagamento do financiamento e também devido à estimativa de maiores receitas com a venda de animais.

O fluxo de caixa da produção integrada segue na Figura 2. 
Figura 2 - Fluxo de caixa da produção integrada

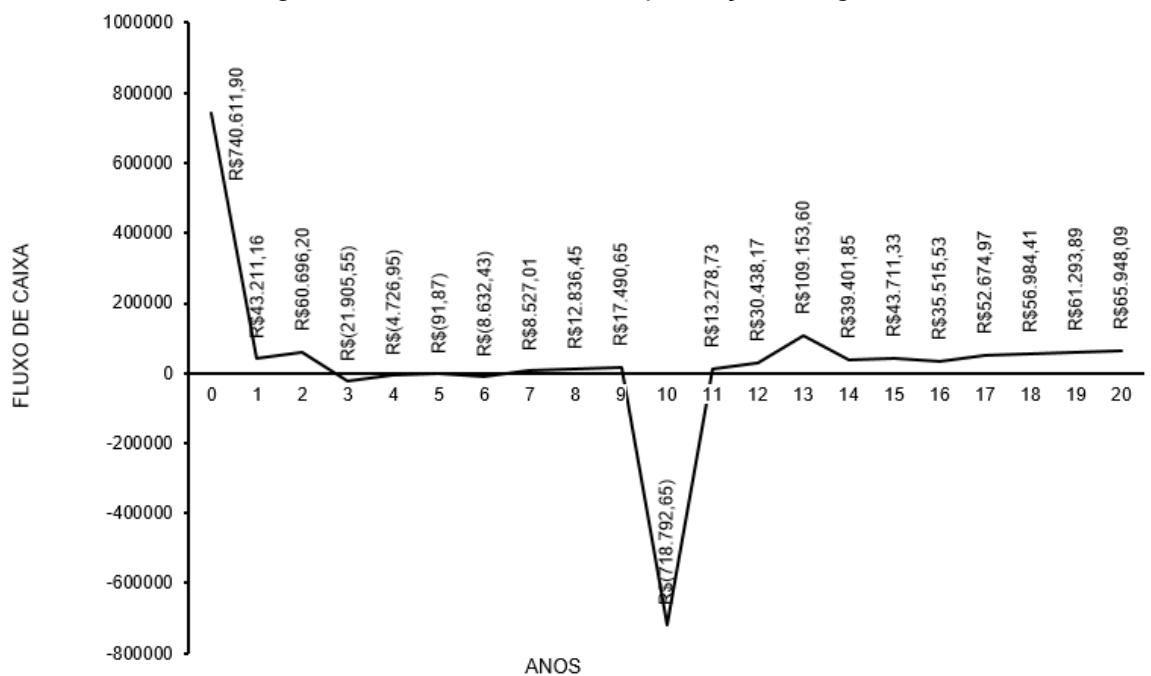

Fonte: Dados da Pesquisa

O custo unitário para produção de $01 \mathrm{~kg}$ vivo de suíno terminado foi de $R \$$ 0,88 na produção integrada. O item de maior participação nesse custo foram as despesas com aquecimento de $\mathrm{R} \$ 0,52$ por kg vivo de suíno, com participação de $68,12 \%$ no custo de produção. Mesmo assim, as despesas com aquecimento por kg produzido seriam remuneradas pelo preço unitário pago pela integradora de $R \$ 4,54$ para o kg vivo de suíno, estimado para 20 anos futuros. Se o custo total de produção do $\mathrm{kg}$ de $R \$ 0,88$ for comparado ao preço unitário pago pela integradora de $R \$ 4,54$ por $\mathrm{kg}$ vivo de suíno, daria lucro de $\mathrm{R} \$ 3,66$ por $\mathrm{kg}$ vivo produzido. Rocha (2006) encontrou resultados diferentes para a produção integrada de suínos, sendo $R \$ 2,08$ o custo médio de produção de um $\mathrm{kg}$, mas com probabilidade de lucro de $35 \%$.

$\mathrm{O}$ custo de produção de um suíno terminado no sistema integrado resultou em $R \$ 713,12$. A média das receitas operacionais estimadas gerou lucro bruto de $R \$$ 78,75 por suíno, o que demonstra prejuízo médio da atividade no sistema integrado em cerca de $R \$ 634,37$ por animal. O resumo dos custos de produção segue na Tabela 7.

Tabela 7 - Custo de produção de suíno no sistema integrado

\begin{tabular}{lcc}
\hline Custos & Custo (R\$/kg) & Participação (\%) \\
\hline COE (custos variáveis) & 0,76 & 12,79 \\
\hline COT (COE + depreciação) & 0,87 & 14,64 \\
\hline CT (COT + custo de oportunidade) & $\mathbf{0 , 8 8}$ & \\
\hline
\end{tabular}

Fonte: Dados da Pesquisa

O projeto de construção e funcionamento do sistema Wean to Finish em São José do Rio Pardo seria interessante para o suinocultor integrado, uma vez que os custos totais de produção seriam compartilhados com a integradora, o VPL seria 
positivo e a TIR remunerando acima da TMA estimada. Assim, o modelo de produção proposto seria viável para o município.

\section{CONCLUSÕES}

Nesse trabalho, a produção independente de suínos no sistema Wean to Finish mostrou-se inviável, devido a obtenção do VPL negativo.

Já a produção integrada encontrou VPL positivo e TIR acima da TMA, mas apresentou prejuízo em relação ao custo de produção do suíno terminado, sendo de alto risco ao suinocultor.

Como o estado de São Paulo se organiza, em sua maioria, em produções independentes, o sistema proposto nesse trabalho poderia ser pensado no futuro, se houver mudança nas organizações das produções.

\section{REFERÊNCIAS}

AGÊNCIA NACIONAL DE ÁGUA (Brasil); COMPANHIA AMBIENTAL DO ESTADO DE SÃO PAULO. Cálculo do preço para expedição de licenças. Brasília, DF: ANA; São Paulo: CETESB, 2018. Disponível em:

https://cetesb.sp.gov.br/licenciamentoambiental/calculo-do-preco-para-expedicao-delicencas. Aceso em 10 mai. 2018.

ASSOCIAÇÃO BRASILEIRA DOS CRIADORES DE SUÍNOS. Mapeamento da suinocultura brasileira. Brasília: $A B C S, 1^{\circ}$ ed., 2016.

ASSOCIAÇÃO BRASILEIRA DOS CRIADORES DE SUÍNOS. Produção de suínos: teoria e prática. Brasília: ABCS, Integrall Soluções em Produção Animal (Coord. Técnica), 1ํod. p. 111-120, 2014.

BRASIL. Decreto n 135, de 01 de dezembro de 2003. Estabelece a transposição para a ordem jurídica nacional a diretiva $n^{\circ}$ 91/630/CEE, do Conselho, de 19 de Novembro, relativa às normas mínimas de proteção de suínos, com as alterações pela diretiva $n^{\circ}$ 2001/88/CE, do Conselho, de 23 de Outubro, e a diretiva $n^{\circ}$ 2001/93/CE, da Comissão, de 9 de Novembro, estabelecendo ainda as normas mínimas de proteção dos suínos alojados para efeitos de criação e de engorda. Brasília: Diário Oficial, Seção I, n. 147, p. 3719, 2003.

BRASIL. Lei no 13.288, de 16 maio de 2016. Dispõe sobre os contratos de integração, obrigações e responsabilidades nas relações contratuais entre produtores integrados e integradores, e dá outras providências. Brasília: Diário Oficial, Seção 1, p. 1, 2016.

BRASIL. Lei no 13.606, de 09 de janeiro de 2018. Institui o Programa de Regularização Tributária Rural [PRR] na Secretaria da Receita Federal do Brasil e na ProcuradoriaGeral da Fazenda Nacional. Brasília: Diário Oficial, Seção 1, p. 2, 2018.

CENTRO DE PESQUISAS METEOROLÓGICAS E CLIMÁTICAS APLICADAS A AGRICULTURA. Clima dos municípios paulistas. Campinas: UNICAMP, 2018. Disponível em: https://www.cpa.unicamp.br/outrasinformacoes/clima_muni_558.html. Acesso em: 10 mai. 2018.

CONSONI, W. Análise produtiva, econômica e sanitária de suínos criados nos sistemas "wean-to-finish" e convencional de produção. 2014. 74 f. Dissertação 
(Mestrado em Ciência Animal) - Centro de Ciências Agroveterinárias, Universidade do Estado de Santa Catarina, Lages, 2014.

COSER, F. J. Contrato de integração de suínos: formatos, conteúdos e deficiências da estrutura de governança predominante na suinocultura brasileira. 2010. 160 f. Dissertação (Mestrado em Agronegócios) - Faculdade de Agronomia e Medicina Veterinária, Universidade de Brasília, Brasília, 2010.

FUNDAÇÃO GETÚLIO VARGAS. Indicadores de preços: IPG. [São Paulo: FGV], 2018.

http://portalibre.fgv.br/main.jsp?lumChannelld=402880811D8E34B9011D92B6B6420 E96. Acesso em: 04 jun. 2018.

GOLLO, V.; VIAN, M.; DIEL, F.J. Análise da viabilidade economica-financeira das atividades leiteira e suinícola em uma propriedade rural. In: XXIV CONGRESSO BRASILEIRO DE CUSTOS, 2017, Florianópolis. Anais [...]. Florianópolis: UFSC, 2017. p. 4289-4399, 2017.

GUIMARÃES, D.; AMARAL, G.; MAIA, G.; et al. Suinocultura: estrutura da cadeia produtiva, panorama do setor no Brasil e no mundo e o apoio do BNDS. Agroindústria/BNDES Setorial, Brasília, n. 45, p. 85-136, 2017.

INSTITUTO BRASILEIRO DE GEOGRAFIA E ESTATÍSTICA. Pesquisa trimestral do abate de animais. Brasília: IBGE, 2018. Disponível em: https://www.ibge.gov.br/estatisticas-novoportal/economicas/agricultura-epecuaria/9203-pesquisas-trimestrais-do-abate-de-animais.html?=\&t=resultados. Acesso em: 12 mar. 2018.

INSTITUTO BRASILEIRO DE GEOGRAFIA E ESTATÍSTICA. São José do Rio Pardo: panorama. Brasília: IBGE, 2018. Disponível em: https://cidades.ibge.gov.br/brasil/sp/sao-jose-do-rio-pardo/panorama. Acesso em: 12 mar. 2018.

INSTITUTO BRASILEIRO DE GEOGRAFIA E ESTATÍSTICA. Índice nacional de preços ao consumidor amplo - IPCA. Brasília: IBGE, 2018. Disponível em: https://www.ibge.gov.br/estatisticas-novoportal/economicas/precos-e-custos/9256indice-nacional-de-precos-ao-consumidor-amplo.html?=\&t=resultados. Acesso em: 24 abr. 2018.

KRUGER, S. D.; BACCIN, R. S.; MAZZIONI, S. Análise da viabilidade econômicofinanceira da atividade suinícola. In: XXIV CONGRESSO BRASILEIRO DE CUSTOS, 2017, Florianópolis. Anais [...]. Florianópolis: UFSC, 2017. p. 4290-4400, 2017.

MARTINS, F.M.; SANTOS FILHO, J.I.; SANDI, A.J.; et al. Coeficientes técnicos para o cálculo do custo de produção de suínos. Embrapa suínos e aves, Concórdia, Comunicado técnico 506, 1 ed. mar. 2012.

MASSARI, J. M. Diferentes padrões de divisões de sexos para alojamento de suínos criados em sistema "wean to finish". 2014. 157 f. Dissertação (Mestrado em Engenharia Agrícola) - Faculdade de Engenharia Agrícola, Universidade Estadual de Campinas, Campinas, 2014. 
MEDEIROS, B. B. L. Bem-estar e desempenho de suínos criados em sistema "wean to finish". 2013. 205 f. Tese (Doutorado em Engenharia Agrícola) - Faculdade de Engenharia Agrícola, Universidade Estadual de Campinas, Campinas, 2013.

MERA, C. M. P.; LORENZINI, R.; WOLLMANN, M. R. Percepção com suinocultores de Tapera/RS sobre o uso de dejetos suínos na lavoura e o impacto ambiental. Extensão Rural, Santa Maria, v. 21, n.1, p.77-100, jan./jun. 2011. Disponível em: https://periodicos.ufsm.br/extensaorural/article/view/5570/3291. Acesso em: $16 \mathrm{abr}$. 2018.

MEYER, L. G.; PAIXÃO, M. A. S. da. Instruções Gerais para Elaboração de um Fluxo de Caixa. 2. ed. Piracicaba: Ed. IPECEGE, ESALQ, 2018.

MIELE, M.; WAQUIL, P.D. Estrutura dos contratos de integração na suinocultura de Santa Catarina. Embrapa suínos e aves, Concórdia, Comunicado técnico 429, 1.ed., mar. 2006.

MINISTÉRIO DA AGRICULTURA, PECUÁRIA E ABASTECIMENTO. INSTITUTO NACIONAL DE METEOROLOGIA. Balanço hídrico climatológico mensal. Brasília, DF: MAOA; INMET, 2018.2 Disponível em: http://sisdagro.inmet.gov.br/sisdagro/app/climatologia/bhclimatologicomensal/index. Acesso em: 16 abr. 2018.

MINISTÉRIO DA AGRICULTURA, PECUÁRIA E ABASTECIMENTO. COMPANHIA NACIONAL DE ABASTECIMENTO. Custos - Suínos - 2016. Brasília, DF: MAPA; CONAB, 2018. Disponível em: https://www.conab.gov.br/info-agro/custos-deproducao/planilhas-de-custo-de-producao/item/1932-custos-suinos-2016. Acesso em 10 maio. 2018.

MORÉS, N. É possível produzir suínos sem o uso de antimicrobianos melhoradores de desempenho?. In: VI CONGRESSO LATINO-AMERICANO DE NUTRIÇÃO ANIMAL, 2014, São Pedro. Anais eletrônicos [...]. São Pedro: CBNA, 2014. Disponível em: https://ainfo.cnptia.embrapa.br/digital/bitstream/item/122662/1/final75. Acesso em: 05 mar. 2018.

ROCHA, D. T. da. Competitividade entre os sistemas integrado e independente de produção de suínos. Orientador(a): Altair Dias de Moura. 2006. 108 f.

Dissertação (Mestrado em Ciências) - Universidade Federal de Viçosa, Viçosa, 2006.

ROCHA JÚNIOR, W. F. et al. Transações entre suinocultores e agroindústrias no Estado de Santa Catarina (Brasil): um exame de contratos sob enfoque institucional. REDES Revista do Desenvolvimento Regional, Santa Cruz do Sul, v. 17, n. 2, p. 229 - 248, 2012.

ROSTAGNO, H. S. et al. Tabelas brasileiras para aves e suínos: composição de alimentos e exigências nutricionais. 4. ed. Viçosa: Ed. UFV, 2017.

SECRETARIA DE AGRICULTURA E ABASTECIMENTO (São Paulo). INSTITUTO DE ECONOMIA AGRÍCOLA. Estatísticas da produção paulista. São Paulo, SP: IEA, 2018. 
http://ciagri.iea.sp.gov.br/nia1/subjetiva.aspx?cod_sis=1\&idioma=1. Acesso em: 12 mar. 2018.

SECRETARIA DE AGRICULTURA E ABASTECIMENTO (São Paulo). INSTITUTO DE ECONOMIA AGRíCOLA. Valor de terra nua. São Paulo, SP: IEA, 2018. Disponível em:

http://ciagri.iea.sp.gov.br/nia1/precor_Mun_SEFAZ.aspx?cod_tipo=1\&cod_sis $=8$.

Acesso em: 12 mar. 2018.

SILVA, M. L.; FONTES, A. A. Discussão sobre os critérios de avaliação econômica: valor presente líquido (VPL), valor anual equivalente (VAE) e valor esperado da terra (VET). Revista Árvore, Viçosa: UFV, v.29, n.6, p.931-936, 2005.

TALAMINI, D.J.D. et al. Custos agregados da produção integrada de suínos nas fases de leitões e de terminação. Revista Custos e Agronegócio online, Recife: UFRPE, v.2, p. 64-83, 2006.

WINCK, C.A.; GODOY, C.L. Viabilidade do fornecimento de água e ração para leitões em lactação no sistema Wean to Finish. Revista PUBVET, Maringá: UEM, v.7, n.16, ed. 239, 2013. 